\title{
O COMÉRCIO, A CIDADE E A EXPANSÃO DA SOCIOECONOMIA SOLIDÁRIA NA MESORREGIÃO TRIÂNGULO MINEIRO/ALTO PARANAÍBA ${ }^{1}$
}

\author{
Renata Rodrigues da Silva ${ }^{2}$ \\ Geisa Daise Gumiero Cleps ${ }^{3}$
}

\section{Resumo}

O comércio pode ser entendido como um dos agentes responsáveis por transformações no espaço, bem como no lugar onde ele ocorre, contribuindo para o desenvolvimento das cidades, estabelecendo relações entre o rural e o urbano. Contudo, o comércio também acentua as diferenças socioeconômicas entre países, contribuindo com a geração de injustiças relacionadas à distribuição de renda e de comercialização. Dessa forma, ressalta-se a necessidade da criação e da efetivação de alternativas referentes à inserção de uma maior parcela da população no mercado de trabalho e, também, de redistribuição mais justa de renda. Por isso, é reconhecida a importância da comercialização dos produtos e serviços resultantes da socioeconomia solidária ou economia solidária. Nesse sentido, este artigo tem como principal objetivo analisar a expansão da socioeconomia solidária em Minas Gerais, bem como a comercialização resultante dessa prática.

Palavras- chave: Socioeconomia Solidária; Comercialização; Triângulo Mineiro/Alto Paranaíba.

\begin{abstract}
Trade is responsible for changes in space and place. It contributes to the development of cities and connects the rural and urban. Trade exacerbates the socioeconomic differences between countries, creating inequalities in income distribution and marketing. It highlights the need to develop alternatives for the integration of the population in the labor market and fairer redistribution of income. Therefore, the marketing of products and services in Partnership economy is important for generating employment and income redistribution more just and
\end{abstract}

\footnotetext{
${ }^{1}$ Este texto faz parte dos resultados obtidos na Pesquisa de PIBIC/CNPq intitulado "O Lugar e as formas de Comercialização dos Produtos e Serviços da Socioeconomia Solidária em Uberlândia - MG”, realizado na Universidade Federal de Uberlândia, no período de 08 /2008 à 07/2009.

2 Graduanda, Universidade Federal de Uberlândia - Instituto de Geografia. NEAT/LAGEA . renatadageo@yahoo.com.br.

${ }^{3}$ Professora Doutora e Coordenadora do Projeto de Pesquisa. Instituto de Geografia - Universidade Federal de Uberlândia. NEAT/LAGEA. gdgumiero@ras.ufu.br.
} 
equitable. Thus, we highlight the purpose of this study is to analyze the expansion of Partnership economy in Minas Gerais and its marketing.

Keywords: Partnership economy; Marketing; Triangulo Mineiro / Alto Paraínaba.

\section{Introdução}

Entende-se por comércio o processo de trocas diretas ou indiretas, iniciado a partir do surgimento do excedente na produção, que se intensificou com a criação e a padronização de moedas, pesos e medidas, bem como pelo surgimento e desenvolvimento das cidades.

Neste sentido, o comércio constitui-se em uma atividade bastante antiga, estando associada aos primórdios da sociedade. O período das Cruzadas e das Grandes Navegações representou um grande avanço para a atividade comercial, que propiciou um importante incremento no desenvolvimento dos países. Nesse sentido, pode-se afirmar que a intensificação dessas atividades possibilitou um importante desenvolvimento econômico, principalmente, para os países pioneiros no comércio internacional como Portugal e Espanha, nos séculos XV e XVI.

A Revolução Industrial também se destaca como outro período histórico que impulsionou o comércio, tendo em vista o surgimento do excedente de produção gerado pela incorporação das máquinas na produção, caracterizando o processo de industrialização. Nesse período, fez-se necessário o surgimento de uma nova distribuição para que os produtos industrializados fossem comercializados, assim, surgem os Bairros Operários e, a partir de então, o comércio se expande para além das áreas centrais, abrindo filiais nestes novos espaços urbanos.

A partir de então se observa um processo de deslocamento do comércio para diferentes áreas da cidade, sendo que, a princípio, a maioria dessas atividades comerciais localizava-se nas áreas centrais das cidades. Porém, devido a alguns fatores como, por exemplo, infraestrutura, acessibilidade, possibilidade de expansão, preço mais acessível dentre outros, encontrados em áreas periféricas, há uma migração do comércio desses locais, não eliminando, evidentemente, o comércio dos centros urbanos, mas, possibilitando uma importante transformação deste comércio que, na maioria dos casos, passou a se destinar a uma clientela economicamente menos favorecida.

Portanto, cabe ressaltar que o comércio sempre esteve associado ao urbano, sendo que, ao passo em que se intensificavam as atividades comerciais, as cidades foram surgindo e se desenvolvendo. A influência do comércio sobre as cidades, nos últimos séculos, ainda mostra-se muito evidente, porém, nota-se também a influência da cidade nas atividades 
comerciais, tendo em vista que, na medida em que essas se desenvolvem e se modernizam, o comércio precisa se reinventar. Dessa forma, a atividade comercial é considerada como um dos agentes responsáveis pelas transformações do espaço urbano bem como do lugar onde ele ocorre.

Contudo, o comércio contribui para acentuar diferenças socioeconômicas e injustiças relacionadas à distribuição de renda. Nesse sentido, ressalta-se a necessidade da criação e efetivação de alternativas referentes à inserção de uma maior parcela da população no mercado de trabalho e, também, de redistribuição mais justa de renda, principalmente em países como o Brasil, com grandes problemas econômicos e sociais.

Dessa forma, com o objetivo de geração de trabalho e renda para a população que se encontra às margens do modo capitalista de produção, surge a socioeconomia solidária ou economia solidária. Essa outra economia encontra-se apoiada por quatro princípios básicos: trabalho coletivo, autogestão, solidariedade e geração de uma atividade econômica.

No âmbito da socioeconomia solidária destaca-se a comercialização dos produtos e serviços resultantes dessa outra economia, uma vez que essa atividade é a principal fonte de renda para os Empreendimentos Econômicos Solidários (EES), entendidos como grupo de trabalhadores que se reúnem em associações, cooperativas ou grupos informais e desenvolvem o trabalho coletivo. Portanto, a comercialização de produtos ou serviços da economia solidária constitui-se como atividade mantenedora dos empreendimentos e, também, como objetivo final dos mesmos.

Assim, torna-se reconhecida a importância da comercialização dos produtos e serviços resultantes da socioeconomia solidária como forma de geração de renda, garantindo uma redistribuição mais justa e eqüitativa da mesma.

Entretanto, há que se ressaltar que a comercialização ainda representa a maior dificuldade enfrentada pelos EES. Porém, trata-se da principal fonte de renda desses empreendimentos, tendo em vista que a maioria deles tem como objetivo a comercialização de seus produtos, ainda que alguns destes empreendimentos sejam voltados exclusivamente para o autoconsumo dos próprios sócios.

A partir das últimas décadas do século XX, observa-se um processo de expansão da socioeconomia solidária em muitos países, principalmente no Brasil. Dessa forma, destaca-se também o surgimento de instituições e órgãos governamentais que apóiam o fortalecimento de experiências de economia solidária no país, como, por exemplo, a Secretaria Nacional de Economia Solidária (SENAES), o Sistema de Informações em Economia Solidária (SIES), o Fórum Brasileiro de Economia Solidária (FBES) dentre outros. 
Assim como no Brasil, a expansão da socioeconomia solidária também é uma realidade no estado de Minas Gerais. Segundo dados da Secretaria Nacional de Economia Solidária (SENAES, 2009), no ano de 2007 esse crescimento foi maior do que o apresentado nos demais estados do Sudeste.

Diante do crescimento da economia solidária no Brasil, sobretudo no estado de Minas Gerais, este trabalho apresenta como principal objetivo analisar a forma de comercialização e expansão da socioeconomia solidária na Mesorregião do Triângulo Mineiro/Alto Paranaíba.

Tal mesorregião foi escolhida para ser analisada tendo em vista o elevado número de Empreendimentos Econômicos Solidários que apresenta, constituindo-se na quarta mesorregião do estado de Minas Gerais com o maior número de empreendimentos, um total de 113, segundo dados da SENAES (2009). Os EES encontrados no Triângulo Mineiro/Alto Paranaíba realizam tanto a comercialização de produtos quanto a prestação de serviços, o que significa um avanço do trabalho coletivo nessa mesorregião, uma vez que as atividades coletivas e o cooperativismo não são muito expressivos nessa localidade.

Para atingir os objetivos propostos, fez-se necessário, inicialmente, um levantamento de dados acerca dos empreendimentos que praticam a Socioeconomia Solidária em Minas Gerais. Para tanto, foram utilizados os dados da Secretaria Nacional de Economia Solidária (SENAES) e do Sistema de Informações em Economia Solidário (SIES); do Instituto Nacional de Reforma Agrária (INCRA); do Ministério do Trabalho e Emprego (MTE); do Ministério de Desenvolvimento Agrário (MDA); da Rede de Comercialização Solidária; da Rede Brasileira de Socioeconomia Solidária; da Cáritas e outros, além de pesquisas de campo nas cidades da Mesorregião que apresentavam o maior número de empreendimentos. Nessas localidades foram aplicados questionários junto a produtores, comerciantes e representantes dos EES.

No que concerne ao referencial teórico básico, na execução desta pesquisa foram utilizados vários trabalhos de autores que têm se dedicado aos estudos da Economia Popular Solidária, do Comércio Solidário e do Consumo Solidário. Entre estes se destacam os trabalhos de Cattani, A. D. (2003); Gaiger, L.I. (1999); Lisboa, A. (1998); Razeto, L. (1993); Singer, P. (2004); Mance (2002) entre outros referenciados no final deste trabalho.

Para que se possa entender o papel da Socioeconomia Solidária no contexto atual, torna-se necessário analisar o processo de desenvolvimento econômico e a influência deste na produção do espaço, na reconfiguração dos territórios e nas novas formas de comercialização engendradas, conforme se segue. 


\section{As Influências da Globalização sobre a Socioeconomia Solidária}

A globalização é uma realidade no cotidiano dos cidadãos. Porém, a mesma ocorre de forma e intensidade diferente, contribuindo para intensificar as desigualdades socioeconômicas e agravar a exclusão social. Trata-se de um processo antigo e que, atualmente, tornou-se mais freqüente em diversas regiões do mundo, inclusive no Brasil. No entanto, nem todos têm acesso aos benefícios advindos da intensificação de tal processo.

Embora a noção de globalização econômica seja amplamente difundida, nota-se o quão seletivo é esse processo, contribuindo para a intensificação da exclusão social, bem como para o aumento das discrepâncias socioeconômicas, principalmente em países com altos índices de concentração de renda como o Brasil. Desse modo, cabe destacar que o processo de globalização é excludente, e, por tal motivo, são criadas alternativas que visam mitigar os problemas enfrentados pelos cidadãos que não estão econômica e socialmente introduzidos no sistema econômico vigente.

Nesse sentido, Santos (2003), atenta para divergências existentes no processo de globalização. Segundo o autor, a globalização pode ser entendida de três formas distintas, a saber: "a globalização como fábula", ou seja, a noção de globalização que os hegemônicos querem que a população acredite, tentando mascarar os problemas advindos com tal processo; "a globalização como perversidade", significando a globalização como a mesma é de fato, ou seja, gerando desigualdades e injustiças para a parcela da população que se encontra às margens do sistema econômico; e "a outra globalização", que representa como esse processo deveria ser, alcançando a totalidade dos cidadãos de forma semelhante econômica, social, política e culturalmente.

Perante as dificuldades oriundas do sistema econômico vigente, bem como da globalização, torna-se necessário à busca por alternativas que visem solucionar o problema do desemprego e da miséria gerados por tais processos. Em meio a essa nova fase de internacionalização econômica, que privilegia apenas algumas parcelas da população, surge então a chamada socioeconomia solidária, ou economia solidária, que se caracteriza como uma opção para estabelecer novas formas de organização da sociedade.

Observa-se assim, que a socioeconomia solidária não está ligada à lógica de mercado, como a economia tradicional que tem como característica a obtenção cada vez maior de lucro. Essa outra economia tem como preocupação central a questão social. No entanto, buscando atender as necessidades básicas dos cidadãos, não descarta também as questões econômicas, políticas e ambientais. 
Devido a fatores como a geração de trabalho e renda, o trabalho coletivo e autogestionário, a distribuição de renda, a incorporação dos excluídos na sociedade dentre outros, é que a socioeconomia solidária encontra-se em processo de expansão.

Diante do exposto nota-se a existência de profundas relações existentes entre globalização e exclusão social, destacando-se a socioeconomia solidária como uma forma alternativa de inserção da população socialmente excluída no mercado de trabalho e, conseqüentemente, na sociedade. Neste sentido, a socioeconomia solidária será aqui retratada tendo como base os princípios de cooperação e de trabalho coletivo, diferenciando-se do sistema capitalista vigente, considerando o trabalhador, dando mais valor ao mesmo do que à sua força de trabalho. A nosso ver, a socioeconomia solidária é uma possível alternativa para uma grande parcela da população excluída do mercado formal de trabalho, visto que valoriza as experiências de trabalho coletivo e autogestionário.

\section{Socioeconomia Solidária: revendo conceitos}

Entende-se por socioeconomia solidária algumas alternativas encontradas para minimizar problemas relacionados ao desemprego crescente, sendo também uma fonte de geração de renda, para parte da população que não é atendida pelo capitalismo ou pelas influências da globalização.

Neste sentido, observa-se que essa outra economia é sustentada por quatro princípios básicos, sendo eles: o trabalho coletivo, através de associações, cooperativas ou grupos informais, que sejam suprafamiliares; a solidariedade, cujos resultados do trabalho sejam divididos de maneira justa entre os membros do grupo (tendo como princípio o fato de que a socioeconomia solidária não visa o lucro, mas com o excedente ou a sobra); a autogestão, os próprios membros do grupo devem gerir o empreendimento e, para que isso ocorra, deve-se eleger um líder para coordenar o trabalho; o desenvolvimento de uma atividade econômica, pois como o empreendimento, na maioria dos casos, é a única fonte de renda dos trabalhadores, deve ter como objetivo garantir que as necessidades básicas do cidadão sejam atendidas, embora hajam empreendimentos voltados para o autoconsumo.

Muitas discussões existem a respeito da socioeconomia solidária, alguns pesquisadores defendem a idéia da economia solidária como forma de resistência ao sistema capitalista. Outros acreditam que a mesma vai de encontro ao próprio modo de produção, ou seja, que defende os interesses do capitalismo. Sendo que, no presente trabalho, adotamos a idéia de economia solidária como uma forma alternativa ao sistema econômico, capaz de suprir as necessidades básicas dos cidadãos e defendendo os interesses dos trabalhadores. 
A economia solidária constitui-se como uma realidade no cotidiano de muitas pessoas em diversos países do mundo, inclusive no Brasil. Entretanto, observa-se que, em alguns casos, ocorrem adaptações do modelo ideal proposto por alguns autores, que concebem a socioeconomia solidária como uma verdadeira utopia. Desse modo, destaca-se o ideal proposto por Singer (2002, p. 10), para a economia solidária. Segundo eles,

A economia solidária é outro modo de produção, cujos princípios básicos são a propriedade coletiva ou associada do capital e do direito à liberdade individual. A aplicação desses princípios une todos os que produzem numa única classe de trabalhadores que são possuidores de capital por igual em cada cooperativa ou sociedade econômica. O resultado natural é a solidariedade e a igualdade, cuja produção, no entanto, exige mecanismos estatais de redistribuição solidária da renda.

Neste sentido, cabe ressaltar que a socioeconomia solidária não se constitui como um modelo revolucionário que visa mudar ou subordinar o sistema atual, caracterizando-se apenas como um projeto que tem como objetivo estruturar uma alternativa econômica, social, política e também cultural. Constata-se assim que, paralelamente ao sistema capitalista, existem formas alternativas que atendem e suprem as necessidades mínimas da parcela da população que se encontra à margem do modo de produção vigente.

Contudo, deve-se considerar que a economia solidária não se configura como a única forma de resistência ao capitalismo, tendo em vista que esse modo de produção nunca se apresentou como um modelo totalitário. Desde a instituição do capitalismo como modo de produção, existiu uma parcela da sociedade que esteve a sua margem, pelo fato de que no capitalismo não há espaço para todos, visto que são as desigualdades sociais e econômicas asseguram sua sobrevivência.

Alguns fatores contemporâneos como, por exemplo, a incorporação de tecnologias no processo de produção, a falência de empresas, as privatizações e a globalização estimulam experiências associativas e de autogestão, tendo em vista que tais fatores contribuem para elevar as taxas de desemprego em diversos países.

De acordo com os dados da SENAES (2008), no Brasil, atualmente, o número de pessoas envolvidas com a economia solidária ultrapassa um milhão e engloba, aproximadamente, 20 mil Empreendimentos Econômicos Solidários.

Se, por um lado, a expansão da economia solidária no país é muito interessante, pois demonstra a capacidade que as pessoas têm para encontrarem soluções capazes de gerar, não apenas emprego e renda, como também diferentes relações de trabalho, por outro lado, essa 
expansão traduz ineficiências, por parte dos governantes, de garantir condições dignas de sobrevivência para a população.

Em relação à socioeconomia solidária há de se considerar também que a mesma não diz respeito apenas às questões relativas ao mercado de trabalho, mas a uma nova visão social, onde os trabalhadores, a partir de experiências coletivas e autogestionárias, não somente apreendem sobre o ato de produzir como também entram em contato com outra realidade pautada em princípios não valorizados no capitalismo como, por exemplo, a noção de solidariedade e de trabalho coletivo.

Dentro da perspectiva dessa outra economia encontram-se diferentes formas de organização do trabalho coletivo, sendo os mais comuns: os grupos informais, desprendidos da documentação formal exigida para estabelecimentos; as associações e as cooperativas. Dentre essas organizações de trabalho, as que mais se destacam na economia solidária são as cooperativas. Nestas o conceito chave é a cooperação, pois agrega valores de colaboração e ajuda mútua.

Assim, diante de todas as desigualdades geradas pelo modo de produção capitalista, faz-se necessário, mais do que pensar em alternativas, colocá-las em prática, no sentido de inserir uma maior parcela da população no mercado de trabalho, sendo fonte de geração de renda e de diminuição de tamanhas injustiças vivenciadas por séculos.

\section{A Socioeconomia Solidária e a Relação Campo - Cidade}

A relação entre o campo e a cidade pode ser entendida como uma relação de dependência, porém essa dependência varia ao longo do tempo. Anteriormente, o campo era visto como produtor de matérias-primas e a cidade era entendida como o local de consumo e industrialização desses produtos. Embora essa situação atualmente ainda ocorra, muitas modificações aconteceram tanto na área rural quanto na área urbana. A instalação de Complexos Agroindustriais (CAIs) e o desenvolvimento de atividades não rurais no campo, são algumas dessas transformações.

De acordo com Andrade (1994, p.53),

[...] até os meados do século XX havia uma grande diferença, uma grande distância entre o meio urbano e o meio rural. Sabia-se que na maior porção da superfície da terra as áreas rurais eram bem extensas e bem menos populosas que as urbanas. O contraste entre esses dois meios era muito grande, de vez que o primeiro logo absorvia as novas técnicas e instrumentos, enquanto o rural permanecia tradicional e arcaico. 
Embora tenha ocorrido à modernização do campo, a comercialização de produtos no meio rural ainda enfrenta dificuldades. Dessa forma, ainda é na cidade que a comercialização é feita com sucesso. Isso também ocorre em relação à socioeconomia solidária.

Neste sentindo, embora, de acordo com o Quadro 1, o maior número de Empreendimentos Econômicos Solidários, identificados e localizados nos municípios da mesorregião Triângulo Mineiro/Alto Paranaíba, esteja localizado em áreas urbanas, um total de 55 EES, deve-se considerar a expressiva existência de tais empreendimentos em áreas rurais, totalizando 40 EES no campo. No entanto, em municípios como Abadia dos Dourados, Campina Verde, Monte Carmelo, Perdizes, dentre outros, o número de empreendimentos da economia solidária no meio rural é superior aos empreendimentos encontrados na área urbana. Porém, em municípios como Uberlândia, Uberaba, Patos de Minas e outros o predomínio de EES ocorre na área urbana.

\begin{tabular}{|c|c|c|c|}
\hline MUNICÍPIOS & RURAL & URBANO & RURAL E URBANO \\
\hline Abadia dos Dourados & 1 & 0 & 0 \\
\hline Araguari & 4 & 4 & 0 \\
\hline Araxá & 0 & 3 & 2 \\
\hline Campina Verde & 2 & 0 & 1 \\
\hline Capinópolis & 0 & 1 & 2 \\
\hline Carmo do Paranaíba & 0 & 5 & 0 \\
\hline Comendador Gomes & 2 & 0 & 0 \\
\hline Estrela do Sul & 0 & 2 & 0 \\
\hline Frutal & 0 & 1 & 0 \\
\hline Grupiara & 0 & 2 & 0 \\
\hline Ibiá & 2 & 0 & 0 \\
\hline Indianópolis & 1 & 0 & 0 \\
\hline Ituiutaba & 0 & 0 & 2 \\
\hline Monte Carmelo & 4 & 3 & 0 \\
\hline Patos de Minas & 10 & 13 & 1 \\
\hline Patrocínio & 0 & 1 & 0 \\
\hline Perdizes & 2 & 0 & 0 \\
\hline Prata & 1 & 0 & 0 \\
\hline Serra do Salitre & 1 & 0 & 0 \\
\hline Tiros & 1 & 0 & 0 \\
\hline Tupaciguara & 0 & 0 & 1 \\
\hline Uberaba & 0 & 6 & 3 \\
\hline Uberlândia & 9 & 14 & 6 \\
\hline TOTAL & 40 & 55 & 18 \\
\hline
\end{tabular}


Mesorregião Triângulo Mineiro/Alto Paranaíba: Número de EES no Meio Rural, Urbano e Rural e Urbano, por Município (2007)

Fonte: SENAES, 2008.

Há de se considerar também que, para que as experiências de socioeconomia solidária se consolidem, alguns EES conciliam atividades em áreas rurais e urbanas. Mesmo nos casos em que a produção da socioeconomia solidária ocorra, exclusivamente, no meio rural, à comercialização se dá, principalmente, em áreas urbanas, intensificando e fortalecendo a relação entre campo e cidade.

\begin{tabular}{|c|c|}
\hline MUNICÍPIOS & $\begin{array}{l}\text { ASSENTAMENTOS E AGRICULTURA } \\
\text { FAMILIAR }\end{array}$ \\
\hline Abadia dos Dourados & 0 \\
\hline Araguari & 3 \\
\hline Araxá & 0 \\
\hline Campina Verde & 2 \\
\hline Capinópolis & 0 \\
\hline Carmo do Paranaíba & 0 \\
\hline Comendador Gomes & 2 \\
\hline Estrela do Sul & 0 \\
\hline Frutal & 0 \\
\hline Grupiara & 0 \\
\hline Ibiá & 2 \\
\hline Indianópolis & 0 \\
\hline Ituiutaba & 0 \\
\hline Monte Carmelo & 1 \\
\hline Patos de Minas & 1 \\
\hline Patrocínio & 0 \\
\hline Perdizes & 2 \\
\hline Prata & 0 \\
\hline Serra do Salitre & 0 \\
\hline Tiros & 0 \\
\hline Tupaciguara & 1 \\
\hline Uberaba & 0 \\
\hline Uberlândia & 7 \\
\hline TOTAL & 21 \\
\hline
\end{tabular}


Observa-se, em muitos casos de experiências ligadas a socioeconomia solidária no meio rural, uma ligação entre essa outra economia e os assentamentos de reforma agrária e a agricultura familiar, uma vez que, alguns dos princípios fundamentais da economia solidária como, por exemplo, a autogestão e o trabalho coletivo, também são princípios norteadores dos assentados e dos pequenos produtores.

De acordo com o Quadro 2, referente ao número de Empreendimentos Econômicos Solidários encontrados em assentamentos de reforma agrária e em experiências de agricultura familiar, destaca-se o município de Uberlândia que apresenta o maior número de EES em pequenas propriedades rurais, sejam em assentamentos ou em pequenos agricultores, totalizando sete EES, seguida por Araguari, com um total de três EES. Destaca-se também, na observação do referido quadro, que alguns municípios como, por exemplo, Abadia dos Dourados, Frutal, Serra do Salitre, Uberaba entre outros, não apresentam nenhum EES que esteja diretamente ligado à Reforma Agrária ou a Agricultura Familiar.

Quando se compara os dados apresentados no Quadro 2, referentes ao número de EES associados aos assentamentos e a agricultura familiar, com os dados contidos no Quadro 1, observa-se que a conciliação entre economia solidária e as experiências de reforma agrária ou a pequena produção ainda é muito limitada, frente ao elevado número tanto de Empreendimentos Econômicos Solidários quanto de assentamentos existentes na região analisada neste trabalho. Entretanto, observa-se que através da comercialização dos produtos e serviços resultantes da socioeconomia solidária reforça-se a relação entre campo e cidade.

\section{O Processo de Comercialização dos Produtos e Serviços Resultantes da Socioeconomia}

\section{Solidária}

Diante de todo o processo de expansão da economia solidária no país, destaca-se também o crescimento da comercialização dos produtos e serviços da mesma, tanto no Brasil quanto, em particular, no estado de Minas Gerais. Porém, a fase da comercialização é apontada pela maioria dos Empreendimentos Econômicos Solidários como a mais difícil etapa enfrentada por esses empreendimentos, seguida pela de obtenção de crédito necessário para manter as atividades desenvolvidas pelos mesmos, de acordo com dados da Secretaria Nacional de Economia Solidária (2009).

Em relação à comercialização encontram-se na economia solidária diferentes formas de venda, variando de um empreendimento para outro. Ou seja, a forma como os produtos são 
comercializados é escolhida pelo próprio empreendimento, levando em consideração as características apresentadas pelos mesmos. Alguns empreendimentos são bem estruturados e, portanto, o processo de comercialização é facilitado. Outros possuem lojas próprias para a venda, porém, nem todos os grupos de trabalho dispõem de muitos recursos e, por isso, apresentam maior dificuldade para a comercialização. Alguns produtos da socioeconomia solidária acabam sendo comercializados como produtos tradicionais, não sendo diferenciados e, por isso, algumas vezes, não podem ser mais valorizados pelos consumidores conscientes de seu papel enquanto agentes responsáveis pela redistribuição de renda.

Entre as principais formas e locais de comercialização desses produtos destacam-se: as lojas de comércio solidário, as feiras (feiras livres ou feiras de economia solidária), as lojas convencionais, os empreendimentos e as lojas de produtores, também, em alguns casos, conhecidas como Casa do Artesão.

No que se refere às lojas de comércio solidário, nota-se uma contradição devido ao fato de que o comércio solidário tem como princípio inserir o pequeno produtor no mercado, o que de fato ocorre, pois cria oportunidades de comercialização de produtos diferenciados que não são valorizados no mercado tradicional. Porém, ao mesmo tempo, muitas lojas especializadas, excluem os que não possuem condições financeiras de adquirir tais produtos. Outro ponto a ser questionado é o fato de que as lojas de comércio solidário fazem o papel de atravessadores, prática que é condenada pelos princípios do comércio solidário. Na maioria dos casos, trata-se de lojas modelo exportação, onde os preços praticados não condizem com a realidade econômica do Brasil, pois os produtos são muitos caros, embora sejam produtos originais e de boa qualidade. Nas lojas de comércio justo os principais produtos comercializados são, principalmente, artesanato e produtos alimentícios diferenciados, como orgânicos e caseiros.

Já as feiras constituem-se como um dos principais locais de comercialização dos produtos econômicos solidários, caracterizando-se como uma válvula de escape para os pequenos produtores, principalmente devido às dificuldades que esses encontram no momento da comercialização. Durante a realização das feiras, os produtores podem comercializar seus produtos como resultantes da socioeconomia solidária, o que permite uma maior valorização das mercadorias, além de garantir a aproximação entre produtores e consumidores. Porém, o que ocorre é que na comercialização em feiras livres o produto da socioeconomia solidária não é diferenciado dos demais. Dessa forma, os produtores são prejudicados, tendo em vista que o processo de produção é diferenciado, o que torna, em muitos casos, mais oneroso, além disso, o resultado das vendas é dividido entre o grupo. 
Algumas instituições que apóiam a economia solidária como a Secretária Nacional de Economia Solidária (SENAES), o Fórum Brasileiro de Economia Solidária (FBES) e os fóruns regionais de economia solidária, incentivam a realização de feiras exclusivas de economia solidária, pois vêem nelas uma boa oportunidade de comercialização dos produtos.

Diante disso, foi estabelecido um programa nacional que apóia a realização de feiras em nível estadual, presente em 22 estados brasileiros e no Distrito Federal. Além dessas feiras estaduais, o programa de promoção do comércio solidário também incentiva as feiras de âmbito nacional. Porém, nem todos os produtores têm condições de exporem seus produtos em feiras específicas de socioeconomia solidária. Por isso, a comercialização de produtos econômicos solidários, ou seja, produtos feitos seguindo alguns princípios específicos como a preocupação ambiental e social, são comercializados juntamente como produtos tradicionais.

Outra forma de comercialização dos produtos solidários é a que ocorre em lojas convencionais, sendo que esses produtos podem ou não ser identificados como resultantes da economia solidária. Como exemplos destacam-se algumas lojas da rede $O$ Boticário e algumas da rede de supermercados Pão de Açúcar, as quais comercializam produtos alimentícios.

Apesar de todos esses modos de comercialização, a forma de venda mais comum dos produtos da socioeconomia solidária ocorre nos próprios empreendimentos, mesmo que estes não possuam lojas em suas dependências. Alguns consumidores têm adquirido o hábito de conhecer os empreendimentos podendo, assim, observarem a forma como os produtos solidários são produzidos.

Existem também lojas de associações de artesãos que adotam princípios da socioeconomia solidária e de comércio solidário. Essas lojas, em diferentes municípios, são designadas por "Casa do Artesão" e comercializam, além do artesanato, produtos alimentícios e bebidas, como licores e cachaça. Nestas lojas são os produtores que produzem e expõem seus produtos para a comercialização. Para isso os artesãos pagam uma contribuição mensal para a loja. Além dessa quantia mensal exigida para a exposição, cerca de $10 \%$ do valor de cada peça vendida também fica com a loja que utiliza esse dinheiro para cobrir gastos como aluguel, energia, contratação de funcionários e outros.

Contudo, entende-se a comercialização da produção como a responsável por disponibilizar os recursos necessários para o funcionamento e a manutenção da socioeconomia solidária, proporcionando, assim, uma distribuição justa de renda, mesmo apesar de todas as dificuldades presentes nesta fase. 


\section{A Expansão da Economia Solidária na Mesorregião do Triângulo Mineiro/Alto Paranaíba}

De acordo com dados da SENAES (2009), a situação de Minas Gerais em relação à socioeconomia solidária sofreu algumas alterações no período de 2005 a 2007. Sendo que, no ano de 2005 o estado ocupava a $3^{\text {a }}$ posição no ranking em números de EES da região Sudeste. Representando $14 \%$ do total da região, ficando à frente apenas do estado do Espírito Santo. Porém, de acordo com novos dados da Secretaria Nacional de Economia Solidária, levantados no ano de 2007, Minas Gerais destaca-se com o segundo estado do Sudeste com maior número de EES, sendo superado apenas pelo estado do Rio de Janeiro.

Atualmente, encontra-se em Minas Gerais um total de 1.236 empreendimentos, espalhados por 199 municípios. Tendo em vista a grande dimensão territorial do estado mineiro, bem como o grande número de municípios pertencentes ao mesmo, compreendendo um total de 853, constata-se que, embora o Atlas da SENAES contribua significativamente para análises relacionadas à socioeconomia solidária, o mesmo ainda não consegue abranger todos os EES existentes. Tal fato pode ser explicado em razão de que muitas pessoas praticam a socioeconomia solidária sem saber do que se trata, ou seja, não conhecem a denominação que foi dada às suas atividades, embora conheçam, na prática, os princípios dessa outra economia.

No que se refere à socioeconomia solidária, algumas mesorregiões do estado mineiro destacam-se mais que outras, sendo elas: Belo Horizonte, Norte de Minas e Vale do Jequitinhonha, podendo ser observado no Quadro 3. Os empreendimentos dessas localidades são mais representativos, mais conhecidos e mais beneficiados pelos projetos de apoio à socioeconomia solidária, tal fato deve-se, dentre outros fatores, às condições econômicas, às condições de pobreza e miséria, maiores que nas demais regiões, além de questões culturais, pois nesta região o espírito cooperativista e coletivista está mais arraigado.

Conforme pode ser observado no Quadro 3, em algumas mesorregiões de Minas Gerais a socioeconomia solidária apresenta maior destaque, como o caso da Mesorregião de Belo Horizonte, com mais de 280 empreendimentos, seguida pelo Norte de Minas com 214, Vale do Jequitinhonha com 157, Triângulo Mineiro e Alto Paranaíba com 113 e Sul e Sudoeste Mineiro com 105 empreendimentos. Em outras localidades, como exemplo a Mesorregião Central, o número de empreendimentos não é tão significativo, apenas dois estabelecimentos de socioeconomia solidária foram encontrados na região; a Mesorregião Oeste também não apresenta um número significativo de EES, quando comparada a outras regiões do estado, tendo apenas 34 empreendimentos. 


\begin{tabular}{|l|c|}
\hline \multicolumn{1}{|c|}{ MESORREGIÕES MINEIRAS } & $\begin{array}{c}\text { QUANTIDADE DE } \\
\text { EES }\end{array}$ \\
\hline Central Mineira & 2 \\
\hline Oeste de Minas & 34 \\
\hline Zona da Mata & 79 \\
\hline Vale Rio Doce & 80 \\
\hline Vale do Mucuri & 82 \\
\hline Noroeste de Minas & 89 \\
\hline Sul Sudoeste de Minas & 105 \\
\hline Triângulo Mineiro e Alto Paranaíba & 113 \\
\hline Jequitinhonha & 157 \\
\hline Norte de Minas & 214 \\
\hline Belo Horizonte & 281 \\
\hline TOTAL & \\
\hline
\end{tabular}

\section{QUADRO 3}

Minas Gerais: Quantidade de Empreendimentos por Mesorregiões, 2008. Fonte: SENAES, 2008.

Assim sendo, existem regiões de Minas Gerais em que o cooperativismo é mais representativo, devendo-se, dentre outros motivos, a questões histórico-culturais que favorecem as experiências de socioeconomia solidária. Porém, em algumas localidades não há presença de ações coletivas, não havendo a valorização do trabalho em grupo e de outros princípios defendidos pela socioeconomia solidária, o que dificulta a identificação das experiências existentes e, até mesmo, impede que grupos solidários sejam criados.

Em relação ao estado de Minas Gerais, mais especificamente à mesorregião do Triângulo Mineiro/Alto Paranaíba, observa-se melhor essa expansão pela qual a socioeconomia solidária tem passado quando se compara os dados, fornecidos pela Secretaria Nacional de Economia Solidária levantados no ano de 2005 com os dados referentes ao ano de 2007, tendo em vista que a participação da mesorregião em questão, em relação a socioeconomia solidária, era inexistente no trabalho realizado pela SENAES em 2005, passando para um total de 113 empreendimentos no ano de 2007, ainda de acordo com o Quadro 3. Portanto, no que se refere à prática, tanto do trabalho coletivo quanto da própria economia solidária, observam-se mudanças em relação ao comportamento de algumas mesorregiões mineiras, relacionadas, dentre outros fatores, ao aumento do desemprego e a maior necessidade de geração de renda.

$\mathrm{Na}$ mesorregião do Triângulo Mineiro/Alto Paranaíba os Empreendimentos Econômicos Solidários não são significativos e fáceis de serem identificados. Porém, em 
relação ao ano de 2005, assim como a realidade de Minas Gerais sofreu alterações no âmbito da socioeconomia solidária, muitas modificações também são observadas em relação ao Triângulo Mineiro/Alto Paranaíba. Essas mudanças devem-se, principalmente, a problemas relacionados à elaboração do Atlas da Economia Solidária no Brasil, visto que os empreendimentos existentes no Triângulo Mineiro e Alto Paranaíba tiveram origem anterior ao ano de 2005, onde foram realizadas as pesquisas resultantes neste atlas.

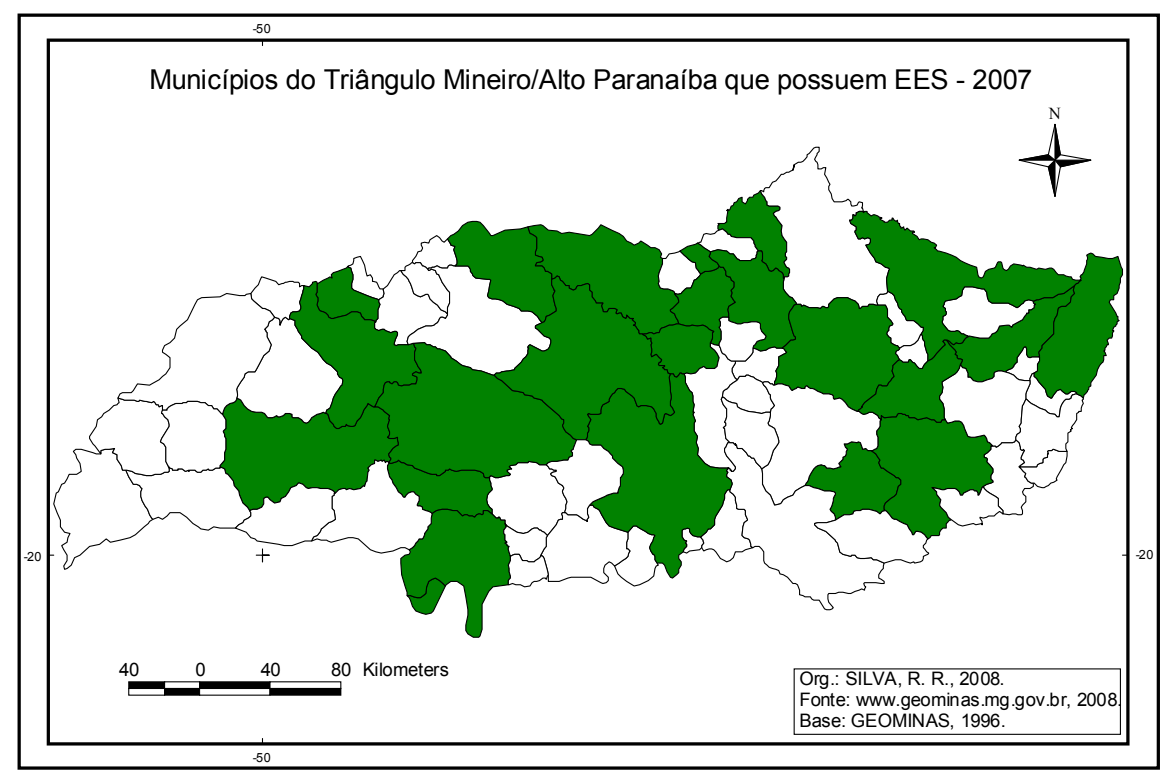

FIGURA 1:

Localização dos EES no Triângulo Mineiro/Alto Paranaíba, 2007. Fonte: SENAES, 2008.

Em 23 municípios, do total de 66 municípios localizados na mesorregião do Triângulo Mineiro/Alto Paranaíba, foram encontrados empreendimentos EES, tais municípios estão destacados na Figura 1. Novamente, destaca-se o município de Uberlândia com um total de 29 EES, distribuídos em áreas urbanas e rurais, como já mencionado.

Porém, o fato de alguns Empreendimentos Econômicos Solidários não terem sido cadastrados pela SENAES (2007), nos municípios da mesorregião Triângulo Mineiro/Alto Paranaíba que não aparecem destacados no mapa, não significa que experiências de socioeconomia solidária não estejam presentes, e sim que muitos levantamentos e pesquisa no âmbito da economia solidária ainda necessitam ser realizados a fim de que compreendamos um pouco mais sobre essa outra economia. 


\section{Considerações Finais}

Diante das injustiças e desigualdades que sustentam o modo capitalista de produção, torna-se necessária a criação e a efetivação de alternativas para a geração de novos postos de trabalho e renda principalmente para a população excluída do mercado de trabalho formal.

Dessa forma, como uma possível solução para a geração de trabalho e renda tem-se a socioeconomia solidária que, atualmente, encontra-se em processo de expansão no Brasil, embora tanto os Empreendimentos Econômicos Solidários quanto os trabalhadores desses empreendimentos ainda enfrentam problemas relacionados à ausência de políticas públicas direcionadas a essa outra economia.

O processo de expansão dessa outra economia também é uma realidade no estado de Minas Gerais, como foi demonstrado ao longo deste trabalho, tornando-se ainda mais evidente em algumas mesorregiões como, por exemplo, no Triângulo Mineiro/Alto Paranaíba, que, mesmo não sendo tradicionalmente uma região de cooperativismo e trabalho coletivo muito expressivo, apresenta um elevado número de Empreendimentos Econômicos Solidários, de acordo com a SENAES (2009).

Apesar de a socioeconomia solidária contribuir não apenas com o crescimento econômico, mas também com o desenvolvimento socioeconômico do país, tal prática ainda encontra muitos desafios e dificuldades, principalmente na fase da comercialização dos produtos e serviços resultantes dessa outra economia que, além de representar a principal fonte mantenedora dos EES, também constitui-se como maior dificuldade desses empreendimentos, o que se deve, dentre outros fatores, à falta de capacitação dos sócios dos mesmos.

Portanto, é imprescindível que políticas públicas sejam criadas ou reforçadas, no intuito de garantir a manutenção e o crescimento das experiências da socioeconomia solidária, a fim de que alternativas ao modo capitalista de produção não sejam apenas pensadas, mas que sejam colocadas em prática, tendo em vista que, inserir a população que se encontra à margem do sistema econômico no mercado de trabalho é uma forma muito mais eficaz de promover o desenvolvimento econômico e social do país, ao contrário do que ocorre com as políticas assistencialistas, que amenizam a situação de desigualdade econômica apenas momentaneamente.

\section{Referências}

ANDRADE, M. C. de. Uma Geografia para o Século XXI. Campinas: Papirus, 1994. 
Atlas de Economia Solidária 2005 - Sistema de Informações em Economia Solidária, disponível em: http://www.sies.mte.gov.br. Acesso em 14 de janeiro de 2009.

Catálogo - trabalhadoras rurais (2007). IV Feira Nacional de Agricultura familiar e Reforma Agrária.

CATTANI, A. D. (org.) A outra economia. Porto Alegre: Voraz Editores, 2003.

CLEPS, G. D. G. O Comércio e a Cidade: novas territorialidades urbanas. In.: Sociedade e Natureza, Uberlândia, ano 16, n. 30, p. 117-132, jun. 2004.

CLEPS, G. D. G.; SILVA, R. R. Comércio Solidário, algumas reflexões. In: Comunicação Científica - I Encontro Nacional de Grupos PET Geografia. Uberlândia (MG), 2006.

. As Redes do comércio solidário em Minas Gerais. In: Comunicação Científica XVIII Encontro Nacional de Geografia Agrária. Rio de Janeiro (RJ), 2006.

A realidade do comércio solidário em Minas Gerais. In: Comunicação Científica III Simpósio Internacional de Geografia Agrária. Londrina (PR), 2007.

Fórum Brasileiro de Economia Solidária, disponível em: http://www.fbes.org.br. Acesso em 14 de janeiro de 2009.

FRANÇA, G.; DIZIMIRA, S. Economia e Dádiva. In.: Organizações \& Sociedade. v. 16, n. 14, p. 141-183, jan/abr 1999.

GAIGER, L. I. O trabalho no centro da Economia Popular Solidária. Caxambu: Unisinos, 1999.

A solidariedade como uma alternativa para os pobres. Disponível em: http://www.pacs.org.br. Acesso em 10 de dezembro de 2008.

INSTITUTO BRASILEIRO DE GEOGRAFIA E ESTATÍSTICA (IBGE). Disponível em: http://www.ibge.gov.br. Acesso em 10 de janeiro de 2009.

LISBOA, Armando. A economia Popular no contexto da grande transformação. Florianópolis: UFSC, 1998.

MARX, K. Introdução [à crítica da Economia política]. Os pensadores. São Paulo: Abril Cultural, 1974. vol. XXXV.

MANCE, E. A. Redes de Colaboração Solidária. Petrópolis: Vozes, 2002.

A consistência das redes solidárias. Ciências Sociais UNISINOS, São Leopoldo, v.

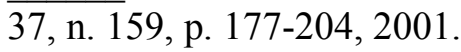


MELO, A. P. G. de. Agricultura Familiar e Economia Solidária: as experiências em gestão de bens comuns e inserção nos mercados por organizações rurais do Estado de Minas Gerais. Dissertação. Mestrado em Administração, área de concentração em Gestão Social. Lavras, 2005.

Ministério do Trabalho e Emprego. Atlas de Economia Solidária no Brasil, 2005, Brasília, 2006.

ORTEGA, A. C.; ALMEIDA FILHO, N. (org). Desenvolvimento Territorial, Segurança Alimentar e Economia Solidária. Campinas: Alínea, 2007.

RAZETO, Luis. Economia de solidariedade e organização popular. In.: GADOTTI, Moacir e GUTIÉRREZ,Francisco. Educação comunitária e economia popular. São Paulo: Cortez, 1993.

REDE SOLIDÁRIA. Disponível em: http:// www.redesolidaria.com.br. Acesso em 14 de janeiro de 2009.

SANTOS, M. Espaço \& método. São Paulo: Nobel, 1985.

Por uma outra globalização do pensamento único a consciência universal. $10^{\mathrm{a}}$ edição. Rio de Janeiro: Record, 2003.

SECRETÁRIA NACIONAL DE ECONOMIA SOLIDÁRIA (SENAES). Disponível em: http://www.mte.gov.br. Acesso em 14 de janeiro de 2009.

SINGER, P. Introdução a Economia Solidária. São Paulo: Editora Fundação Perseu Abramo, 2002.

Economia Solidária. In: CATTANI, A. D. A outra economia. Porto Alegre: Veraz Editores, 2003.

SISTEMA DE INFORMAÇÕES EM ECONOMIA SOLIDÁRIA. Disponível em: http://www.sies.mte.gov.br>. Acesso em 14 de janeiro de 2009.

VASCONCELOS, T. A. C. de. A economia solidária na construção social do desenvolvimento territorial. In: ORTEGA, A. C.; ALMEIDA FILHO, N. Desenvolvimento Territorial, Segurança Alimentar e Economia Solidária. Campinas: Alínea, 2007. 